\title{
LINGUAGEM E RAÇA
}

\section{LANGUAGE AND RACE}

\section{Letícia Fraga* Aparecida de Jesus Ferreira**}

Abordar a temática da raça, neste momento, é de fundamental importância. Embora já tenhamos, no país, vários avanços históricos com relação a questões raciais, como, por exemplo, políticas públicas e políticas linguísticas que evidenciam a necessidade de trazer para o contexto brasileiro a questão da raça como central na elaboração dessas normativas, passamos por um período difícil, tanto nacional como internacionalmente. Por essa razão, demarcar esse espaço é necessário para que possamos garantir que reflexões críticas estejam presentes, já que "o racista numa cultura com racismo é por esta razão normal" (NASCIMENTO, 1978, p. 85 apud MILANEZ et al., 2019, p. 2165).

Não existe história do Brasil sem racismo, principal motivador da escravização dos povos indígenas e africanos.

A doença do racismo, essa espécie de epidemia global do racismo se originou na nossa separação da natureza, quando nós nos separamos da natureza a ponto de não compartilharmos mais com a natureza a riqueza da diferença. Quando se disse que a diferença é o outro, é a impossibilidade de aceitar a diferença, de aceitar o outro como diferença - isso gerou o que nós reconhecemos historicamente como racismo (KRENAK in MILANEZ et al., 2019, p. 2172).

Mas a terminologia raça, que é construída e reconstruída dia a dia social, histórica, cultural e discursivamente, através das nossas relações sociais, ainda tem significado contestado, a tal ponto de "os trabalhos que mostram as consequências (e a continuação) dessa escravidão [receberem] pouca atenção" (MILANEZ, 2019, p. 2166), o que é muito grave, pois elas seguem entre nós de inúmeras formas.

Eventos recentes, como, por exemplo, o assassinato de Mariele Franco, a morte, por sufocamento, de George Floyd nos Estados Unidos, do menino João Pedro, que foi deixado sozinho no elevador pela patroa, enquanto a mãe passeava com o cachorro da patroa e de João Alberto, que foi espancado até a morte dentro de um supermercado, bem como os inúmeros assassinatos dos Kaiowa e Guarani no Mato Grosso do Sul são motivados por racismo. Ou seja, se essas pessoas fossem brancas, o que ocorreu com elas não teria ocorrido.

Sendo assim, falar sobre raça é afirmar enfaticamente que ela é um demarcador de corpos que permite às pessoas viver ou morrer.

Essa questão do genocídio começa quando os europeus chegaram aqui e disseram: "Não são nada, nem são gente, nem são humanos, que não têm fé, porque não tem lei, porque não tem rei. Então são o que? São nada". Daí pra cortar a cabeça ou partir ao meio com um facão ou atravessar com uma bala não faz muita diferença, porque a morte já foi decretada, foi executada antes (GAMELA in MILANEZ et al., 2019, 2172).

Quando falamos sobre raça, não nos referimos somente a pessoas Indígenas ou negras, que são as pessoas pretas e pardas de acordo com o IBGE - grupos que compõem $56 \%$ da população brasileira. Falamos também em raça branca, pois as pessoas brancas também são racializadas, bem como das pessoas amarelas, que são as asiáticas.

De uma forma ou de outra, por conta do momento histórico em que vivemos atualmente, a morte de algumas dessas pessoas repercutiu muito. O caso de Mariele Franco é relembrado em vários momentos. Uma rua, que ficou conhecida nacional e internacionalmente, já foi criada em sua homenagem. A morte de George Floyd gerou o movimento Black Lives Matter que, por sua vez, provocou vários protestos realizados nos Estados Unidos e em outros países, inclusive no Brasil, com grandes repercussões, mesmo que no Brasil mortes de homens negros ocorram diariamente. O caso do menino João Pedro promoveu reflexões sobre o ocorrido e deu origem a um documentário sobre vidas negras, cuja história foi recontada por uma atriz brasileira. A morte de João Alberto,

\footnotetext{
* Universidade Estadual de Ponta Grossa (UEPG), Ponta Grossa, PR, Brasil. leticiafraga@gmail.com Orcid: https://orcid.org/0000-0003-4818-9407

** Universidade Estadual de Ponta Grossa (UEPG), Ponta Grossa, PR, Brasil. aparecidadejesusferreira@gmail.com Orcid: https://orcid.org/0000-0002-3728-0793
} 
conhecido como "Beto", gerou manifestações na frente do supermercado onde a violência ocorreu, bem como em outras lojas da mesma franquia espalhadas pelo Brasil.

Já as mortes de pessoas indígenas, por mais violentas que sejam, costumam sofrer de quase absoluta invisibilização, especialmente na mídia, que alega desconhecer a realidade indígena, mesmo que os próprios indígenas denunciem incansavelmente a violência de que são vítimas. E se os indígenas não são ouvidos, abre-se espaço para que apenas seus algozes, ruralistas, missionários, mineradoras e outros, se manifestem.

Independentemente de serem mais ou menos visibilizadas, o fato de essas mortes ocorrerem na quantidade em que ocorrem mostra que os efeitos do racismo não são individuais, mas estruturais em nossa sociedade, já que estão relacionadas ao que foi construído social, histórica, cultural e discursivamente sobre o que é ser uma pessoa negra ou indígena no Brasil e também em outros contextos.

É a construção discursiva do racismo que torna raça e linguagem indissociáveis. Não há como pensar em raça sem pensar em linguagem e não há como falar sobre linguagem sem falar em raça. A pessoa que fala e com quem se fala e o lugar onde se fala produzem sentidos que evidenciam questões de poder, pois trata-se de corpos racializados (negros, indígenas, brancos, amarelos), produzindo discursos em diversos espaços sociais.

Um dossiê sobre raça e língua(gem) na revista Trabalbos em Linguística Aplicada possibilita que pesquisas no campo da linguística aplicada tenham maior evidência, bem como incentiva que mais pessoas desenvolvam trabalhos a respeito dessa temática, que é cada vez mais necessária, pois o Brasil é um país com várias raças, com predominância da raça negra. Por isso é importante que pessoas de todas as raças se vejam nas pesquisas que, por sua vez, precisam ser referência em cursos de graduação e pós-graduação (FERREIRA, 2019).

Considerando essa necessidade, este dossiê é composto por 12 textos, que abordam a temática do dossiê a partir de diferentes perspectivas.

Glenda Melo, no texto "Performativity of race intersected by gender and sexuality in a conversation circle among black women", mobiliza o conceito de performatividade racial intersetada por gênero e sexualidade, para analisá-lo na interação entre mulheres negras em um círculo de conversação online. Sua análise se apoia no conceito de performatividade dos estudos austinianos e butlerianos e nos conceitos de raça, articulados com outros marcadores discursivos-corporais indicados por hooks (1995), Bento (2002), Mbembe (2014, 2018), Pacheco (2013), entre outros. A análise mostra que os participantes cruzam performatividade racial com gênero e sexualidade no processo de compreensão das peculiaridades de suas próprias existências em diferentes contextos e momentos de suas vidas.

Talita Oliveira, no artigo "Aspectos da branquidade e os atravessamentos da amabilidade artificiosa na mídia televisiva: o caso do RJ-Móvel", problematiza a hipervalorização da branquidade e suas implicações na vida em sociedade, principalmente no que toca à condição de subalternização do povo negro. Sua análise vai na contramão dos estudos que tendem a manter seu foco na investigação do racismo, por meio de uma perspectiva que tem como ponto de conflito a negritude. O corpus é um veículo da mídia televisiva, o quadro RJ-Móvel, transmitido pelo diário telejornalístico local RJ-TV, da Rede Globo de Televisão. Traçando um diálogo com as categorias de Fanon ([1952] 2008), mobilizadas na obra "Pele Negra, Máscaras Brancas" - a saber: amabilidade artificiosa, primitivização da pessoa negra e a caricata espetacularização da negritude e da pobreza, a pesquisadora mostra que o discurso midiático hegemônico performa assistencialismo, produz e reproduz - entre outros modos de estereotipação - práticas racistas.

Isabela Ramalho Orlando, no texto "Línguas indígenas em pauta na aula de inglês: possibilidades para uma educação linguística crítica", apresenta a experiência de um workshop sobre línguas indígenas brasileiras, realizado no contexto de um curso de inglês oferecido em uma universidade pública. No artigo, buscou identificar e analisar os impactos afetivos que essa experiência produziu nos estudantes, a partir de suas falas e de suas produções textuais sobre o workshop. A partir de uma visão discursiva da linguagem (BAKHTIN, 2004), a experiência descrita mostra que os estudantes tiveram oportunidade de refletir sobre suas próprias língua e cultura e sobre seu processo de aprendizagem de inglês, de modo que vai ao encontro de um ensino de línguas antirracista.

Joelma Silva Santos, no texto "Formação de professores de inglês para abordagem de questões étnico-raciais: práticas planejadas e práticas manifestas", descreve conteúdos, metodologia e teorizações derivadas das aulas de um curso de extensão sobre as questões étnico-raciais e culturas de matriz africana no ensino de inglês. Como uma contingência do grupo, parte das aulas voltou-se para o compartilhamento de narrativas de discriminação, de modo que se instaurou o momento bealing storytelling como metodologia necessária à formação. A experiência não 
só ofereceu base teórica para os/as professores/as abordarem as questões sociais, históricas e culturais referentes ao negro, mas também aguçou sua percepção para eventos cotidianos de racismo aos quais já haviam assistido, escutado ou vivenciado dentro e fora da sala de aula.

Gabriel Nascimento, no texto "Entre o lócus de enunciação e o lugar de fala: marcar o não-marcado e trazer o corpo de volta na linguagem", mostra que, apesar de parecerem conceitos primos, lócus de enunciação e lugar de fala são produtos de tendências de pensamento distintas. No artigo, o autor navega entre os sentidos de lócus de enunciação (MIGNOLO, 2000) e lugar de fala (RIBEIRO, 2017) para compreender como a linguagem constrói a racialização e naturaliza marcado e não-marcado por meio dela. Para isso, examina ambos os conceitos, a partir de suas delimitações históricas, as similaridades e diferenças entre si, bem como pontos de encontro teórico. Por fim, o pesquisador propõe dispositivos como trazer o corpo de volta, roubado pela colonialidade, e marcar o nãomarcado, como forma de ligar o lugar de fala ao lócus de enunciação.

Dánie Marcelo de Jesus e Gabriel Oliveira, no texto "Questões étnico-raciais em discursos em torno da virilidade masculina negra em contos homoeróticos", analisam a naturalização de um determinado discurso de virilidade masculina negra em contos homoeróticos publicados na Internet, a partir da problematização da questão racial (bell hooks, 1995; FREITAS, 2011; FANON, 2008 MBEMBE 2018; WIEVIORKA, 2018), da perspectiva da noção de discurso (FOUCAULT, 2012; MAINGUENEAU, 2010) e de construções de sentido de virilidade e seus efeitos ao longo da História (TAMAGNE, 2012; THUILLIER, 2012). A análise de 10 contos gays mais votados pelos leitores do portal "Conto Erótico" sugere que a fixação identitária sofrida por homens negros acaba reforçando o racismo estrutural, que, no Brasil, vem sendo enfatizado desde o estabelecimento das relações hierárquicas entre colonizadores europeus brancos e escravos africanos negros no decurso de séculos de escravidão oficial. Ainda hoje isso constrói um efeito de sentido objetal sobre o negro, posicionando-o como objeto de desejo na teia imaginária.

Thaís Elizabeth Pereira Batista, no texto "Intersecções entre ideologias linguísticas e raciolinguísticas na manutenção de hierarquias raciais", aborda intersecções entre raça e língua em sociedades racializadas. Ela adota uma perspectiva decolonial, em que faz reflexões acerca do conhecimento gerado por indígenas e quilombolas no contexto acadêmico. Em suas considerações, Thaís percebe o seu lugar de privilégio por ser uma pessoa branca, reconhece que não está no mesmo local social das pesquisadoras negras e quilombolas e demonstra que ter discutido sobre colonialidade foi importante para relacionar as questões de ideologias linguísticas e hierarquias raciais.

Maria Regina de Lima Gonçalves Oliveira e Ariovaldo Lopes Pereira são autores do texto "Disputar a "nega'": uma análise da expressão popular na perspectiva dos estudos de gênero, discurso, raça e classe social". Na reflexão que fazem, Oliveira e Pereira discutem a expressão "disputar a nega" e para isso se utilizam da análise de discurso crítica, principalmente para entender quais são os discursos ideológicos que estão em disputa quando a expressão é utilizada. O resultado das análises permitiu evidenciar as intersecções entre gênero, raça negra e classe social.

Pedro Lôbo dos Santos e Eduardo Dias da Silva, no artigo "A educação escolar indígena como fortalecimento da identidade cultural dos Potiguara da Paraíba/Brasil - Considerações Iniciais", trazem reflexões sobre o fortalecimento da identidade étnico-cultural dos indígenas Potiguara a partir de um olhar de uma escola estadual de ensino fundamental e médio localizada na Paraíba. Nas reflexões estão presentes experiências pedagógicas interculturais.

Caroline Vieira Rodrigues, no artigo "Sou um corpo estranho no conjunto": narrativas de um estudante negro migrante em uma universidade brasileira", faz reflexões em que problematiza a presença do aluno negro migrante na universidade. A pesquisa está dentro do escopo da Linguística Aplicada Crítica e alinha as questões abordadas com linguagem, racialidade e decolonialidade. As narrativas de um estudante que entrou na universidade por uma política de inclusão de migrantes refugiados e com visto humanitário a pesquisa demonstram como é a vida do estudante neste espaço, que está permeada por silenciamentos e exclusão.

Leonardo da Silva e Priscila Fabiane Farias, no artigo "A literatura de mulheres negras como direito humano: reflexões sobre o desenvolvimento da consciência crítica no contexto de um projeto de extensão para mulheres em privação de liberdade", trazem resultados das ações de um projeto de extensão, em que se consideram as reflexões de Paulo Freire para trazer o pensamento crítico sobre questões de raça e gênero. As mulheres em 
privação de liberdade tiveram acesso a três obras de escritoras negras e a experiência demonstrou a importância de atividades culturais e literárias.

Kleber Aparecido da Silva e Maria Carmem Aires Gomes, na entrevista "Intersectionality, epistemic oppression and resistance: an interview with Patrícia Hill Collins", abordam as experiências da pesquisadora Patricia Hill Collings, conhecida mundialmente pela obra Pensamento feminista negro. Na entrevista, Patricia Hill Collings rememora suas experiências desde menina até o momento atual, trazendo principalmente questões da sua identidade racial negra interseccionadas com a sua identidade de mulher no contexto estado unidense. Patricia Hill Collings reflete também sobre decolonialidade e interseccionalidade, sempre as atrelando às suas próprias experiências de mulher negra, professora da educação básica, ativista, professora universitária e pesquisadora.

\section{REFERÊNCIAS}

BATISTA, T. E. P. Intersecções entre ideologias linguísticas e raciolinguísticas na manutenção de hierarquias raciais. Trabalbos em Linguística Aplicada, Campinas, SP, v. 60, n. 1, [s.d.]. Disponível em: https://periodicos.sbu.unicamp.br/ojs/index.php/tla/ article/view/8661799. Acesso em: 31 mar. 2021.

FERREIRA, Aparecida de Jesus. Social identities of black females in English language textbooks used in Brazil And Cameroon: Intersectionalities of race, gender, social class and critical racial literacy. Revista X, v. 14, n. 4, p. 20-40, 2019.

FRAGA, L.; FERREIRA, A. de J. Linguagem e Raça. Trabalhos em Linguística Aplicada, Campinas, SP, v. 60, n. 1, [s.d.]. Disponível em: https://periodicos.sbu.unicamp.br/ojs/index.php/tla/article/view/8665126. Acesso em: 31 mar. 2021.

JESUS, D. M. de; OLIVEIRA, G. . Questões étnico-raciais em discursos em torno da virilidade masculina negra em contos homoeróticos. Trabalhos em Linguística Aplicada, Campinas, SP, v. 60, n. 1, [s.d.]. Disponível em: https://periodicos.sbu. unicamp.br/ojs/index.php/tla/article/view/8661910. Acesso em: 31 mar. 2021.

MELO, G. C. V. de. Performatividade de raça interseccionada por gênero e sexualidade em uma roda de conversa entre mulheres negras. Trabalbos em Linguística Aplicada, Campinas, SP, v. 60, n. 1, [s.d.]. Disponível em: https://periodicos.sbu.unicamp.br/ ojs/index.php/tla/article/view/8662006. Acesso em: 31 mar. 2021.

MILANEZ, Felipe et al. Existência e Diferença: O Racismo Contra os Povos Indígenas. Rev. Direito Práx., Rio de Janeiro, v. 10, n. 3, p. 2161-2181, Set. 2019. Disponível em <http://www.scielo.br/scielo.php?script=sci_arttext\&pid=S217989662019000302161 \&lng $=$ en\&nrm=iso $>$. Acesso em 26 Mar. 2021.

NASCIMENTO, G. Entre o lócus de enunciação e o lugar de fala: marcar o não-marcado e trazer o corpo de volta na linguagem. Trabalhos em Linguística Aplicada, Campinas, SP, v. 60, n. 1, [s.d.]. Disponível em: https://periodicos.sbu.unicamp.br/ojs/ index.php/tla/article/view/8661808. Acesso em: 31 mar. 2021.

OLIVEIRA, M. R. de L. G.; PEREIRA, A. L. "Disputar a 'nega": uma análise da expressão popular na perspectiva dos estudos de gênero, discurso, raça e classe social. Trabalhos em Linguística Aplicada, Campinas, SP, v. 60, n. 1, [s.d.]. Disponível em: https://periodicos.sbu.unicamp.br/ojs/index.php/tla/article/view/8661761. Acesso em: 31 mar. 2021.

ORLANDO, I. R. Línguas indígenas em pauta na aula de inglês: possibilidades para uma educação linguística crítica. Trabalhos em Linguística Aplicada, Campinas, SP, v. 60, n. 1, [s.d.]. Disponível em: https://periodicos.sbu.unicamp.br/ojs/index.php/tla/ article/view/8661821. Acesso em: 31 mar. 2021.

RODRIGUES, C. V. "Sou um corpo estranho no conjunto": narrativas de um estudante negro migrante em uma universidade brasileira. Trabalhos em Linguística Aplicada, Campinas, SP, v. 60, n. 1, [s.d.]. Disponível em: https://periodicos.sbu.unicamp. br/ojs/index.php/tla/article/view/8661862. Acesso em: 31 mar. 2021.

ROSA, P. T.; OLIVEIRA, T. de. Aspectos da branquidade e os atravessamentos da amabilidade artificiosa na mídia televisiva: o caso do RJ-Móvel. Trabalhos em Linguística Aplicada, Campinas, SP, v. 60, n. 1, [s.d.]. Disponível em: https://periodicos.sbu. unicamp.br/ojs/index.php/tla/article/view/8661810. Acesso em: 31 mar. 2021. 
SANTOS, J. S. Formação de professores de inglês para abordagem de questões étnico-raciais: práticas planejadas e práticas manifestas. Trabalhos em Linguística Aplicada, Campinas, SP, v. 60, n. 1, [s.d.]. Disponível em: https://periodicos.sbu. unicamp.br/ojs/index.php/tla/article/view/8661892. Acesso em: 31 mar. 2021.

SANTOS, P. L. dos .; SILVA, E. D. da. A educação escolar indígena como fortalecimento da identidade cultural dos Potiguara da Paraíba/Brasil: considerações iniciais. Trabalhos em Linguística Aplicada, Campinas, SP, v. 60, n. 1, [s.d.]. Disponível em: https:/periodicos.sbu.unicamp.br/ojs/index.php/tla/article/view/8661506. Acesso em: 31 mar. 2021.

SILVA, L. da; FARIAS, P. F. . A literatura de mulheres negras como direito humano: reflexões sobre o desenvolvimento da consciência crítica no contexto de um projeto de extensão para mulheres em privação de liberdade. Trabalhos em Linguística Aplicada, Campinas, SP, v. 60, n. 1, [s.d.]. Disponível em: https://periodicos.sbu.unicamp.br/ojs/index.php/tla/article/ view/8661765. Acesso em: 31 mar. 2021.

Recebido: 29/3/2021

Aceito: $29 / 3 / 2021$

Publicado: 30/3/2021 